\title{
Editorial
}

\section{The scientific journal 'Ciência e Tecnologia de Alimentos' internationalizes its name to Food Science and Technology}

Current year 2013 is evidencing several changes in our scientific journal. The first has been the change of its title from 'Ciência e Tecnologia de Alimentos' to Food Science and Technology. We are convinced that this change will internationalize further our journal since the title in English will be noticed by researchers worldwide. In fact, our aim is to make the journal accessible to all the scientific community involved in Food Science and Technology from all parts of the world. We may share the benefits of this science which is so useful to humanity.

Another change occurs in Instruction for Authors, which will make publication of articles faster within the context of the journal's internationalization. Food Science and Technology will be exclusively in English and there will be no need for title and abstract in Portuguese when submitting an article. Other alterations will comprise the Paper structure, Reviewing the manuscript structure and Information provided, which will be the author's responsibility. Original manuscripts should not exceed 16 pages (excluding the references). Further, quotes within the text will be given differently. References should be cited in numerical order according to their order of appearance within the text corresponding to a list of references at the end. They should be numbered consecutively ensuring that the numbered citations will not start again on each page. References in the articles should be listed according to the Vancouver Norms. (http://www.ncbi.nlm.nih.gov/books/NBK7256/?amp=\&depth=2). However, papers which are still to be published or in review should not be included in the references. The names of all authors should be listed and the 'et al.' will not be required any more. According to the SBCTA's Editorial Board, accepted papers which do not follow the standard references style or provide incomplete information WILL NOT BE PUBLISHED until the references comply with norms.

Although Food Science and Technology receives funding from the Brazilian foundations CNPq-CAPES and FAPESP, funds are insufficient to cover total publication costs. As from June 2013 the journal Food Science and Technology (Campinas) will publish an article accepted for publication according to rates below: USD 220.00 - non-members of SBCTA; USD 200.00 - at least one author should be an SBCTA member and should have paid his/her annual membership fee to be eligible for the discount; USD 180.00 - at least two authors should be SBCTA members and should have paid their annual membership fee to be eligible for the discount; USD 160.00 - three authors should be SBCTA members and should have paid their annual membership fee to be eligible for the discount; USD 140.00 - at least four authors should be SBCTA members and should have paid their annual membership fee to be eligible for the discount.

Contributing authors should convert the commercial dollar rate of the date of deposit into Brazilian real. The publication process will not begin until the fee for the accepted paper has been received. Fees may be paid as follows: Payment within Brazil: the invoice will be sent to the Editor by e-mail; International payment: PayPal invoice sent to the Editor by e-mail.

One of the criteria for the non-publication of articles is their local and regional focus of analysis, such as "Qualidade do leite comercializado na cidade de Maringá-PR". Articles should contain novelty in research and a clear experimental design.

The greatest difficulty for the Editorial Board is peer reviewing. Most reviewers fail to answer the invitation or, when they do so, hand it out late. These attitudes cause delay in the analysis of an article and its publication since other reviewers have to be chosen and contacted. If the process were faster, it would reduce time to publish an article in the journal. Four months are required if the process is successful in all its stages.

In 2012 the number of articles sent for publishing to Food Science and Technology was 227, with a rejection rate of 67\%. The same rates are in evidence during 2013. Citations on ISIWEB in 2011 were 340 and increased to 418 in 2012. Citations in SCOPUS for 2011 were 528 and increased to 640 in 2012. Therefore in 2011 there was an increase of 0.221 and 0.476 respectively in JCR (ISIWEB) and SNIP (SCOPUS), with higher rates in 2012 when based on the rising number of citations.

The 2013 QUALIS CAPES evaluation shows the following levels of Food Science and Technology: B1 in Agrarian Sciences I; Interdisciplinary; Environmental Sciences; Engineering I and Engineering III. B2 in Animal Science; Engineering II; Biodiversity; Community Health and Nutrition. B3 in Chemisty; Veterinary Medicine; Medicine II; Pharmacy, Dentistry and Food Sciences. Food Science and Technology rose a notch in Chemistry Qualis rate and went down one notch in Food Sciences, our focus.

In spite of this temporary setback for Food Science and Technology by the CAPES committee for Food Science, I would like to invite all researchers involved in post-graduate courses to submit articles with novel aspects and methodologies to our journal Food Science and Technology since I am sure that the journal will once more return to a better and a higher grading in scientific importance.

I would also invite all researchers involved in Food Science and Technology to be members of the Brazilian Society for Food Science and Technology so that our society will continue to be a strong and united community with relevant importance in Brazil.

Nilson Evelázio de Souza Chief Editor of Food Science and Technology

Eliane Badiale Furlong

Deputy Editor of Food Science and Technology 